\title{
Resultados y tratados de libre comercio entre economías de diferente tamaño: caso EEUU-Colombia ${ }^{1}$
}

\author{
Luis Nelson Beltrán Mora \\ PROFESOR INVESTIGADOR DE LA ESCUELA SUPERIOR DE ADMINISTRADOR PÚBLICA (ESAP) \\ luis.beltran@esap.edu.co Inbeltran@gmail.com
}

\begin{abstract}
Jaime Alberto Gómez Walteros
PROFESOR CO-INVESTIGADOR DE LA ESCUELA SUPERIOR DE ADMINISTRACIÓN PÚBLICA (ESAP)

jaime.gomez@esap.edu.co jaime.albertogomezwalteros@outlook.es
\end{abstract}

Resumen: El propósito de este trabajo es analizar la negociación del tratado de libre comercio (TLC) firmado entre Colombia y EEUU, el cual ha tenido efectos desfavorables para Colombia. Este tema se aborda a la luz de las diversas teorías y enfoques acerca del comercio internacional e integración económica; el déficit comercial acumulado de 7.908 millones de dólares presentado durante los últimos cuatro años, señala que el TLC afecta el aparato productivo nacional, especialmente el sector agropecuario e industrial, resultados que ameritan una revisión urgente del Tratado.

Palabras clave: TLC, déficit comercial, comercio internacional.

Clasificación JEL: F13, C32, F14

Abstract: The purpose of this work is to analyze the negotiation of the free trade agreement (FTA) signed between Colombia and the US, which has had unfavorable effects for Colombia. This issue is addressed in the light of the various theories and approaches about international trade and economic integration; The accumulated trade deficit of 7,908 million dollars presented during the last four years, indicates that the FTA affects the national productive apparatus, especially the agricultural and industrial sector, results that merit an urgent revision of the Treaty.

Key words: FTA, trade deficit, international trade.

1. El presente trabajo es un producto académico parcial del grupo de investigación consolidado: Globalización y Finanzas Públicas, Proyecto: “TLC con EEUU e Impacto en el Posconflicto", participaron como investigadoras Esmeralda González Londoño, Yuli Natalia Barrero Nieto y Lenis Milena Hernández, Administradoras Públicas de la Escuela Superior de Administración Publica, E 


\section{Introducción}

l presente ensayo pretende mostrar que el Tratado de Libre Comercio (TLC) entre Colombia y EEUU, firmado en el año 2006 con vigencia de mayo de 2012, ha resultado desfavorable, a la vista de los resultados obtenidos hasta la presente. Este tema reviste especial importancia tanto a nivel académico como por parte de los gremios involucrados, bien desde la oferta o la demanda, igualmente del lado gubernamental por cuanto una vez entró en vigencia el tratado, se ha observado un déficit comercial para Colombia, que puede estar explicado por la rebaja de aranceles a las importaciones y la baja competitividad de Colombia frente a EEUU. Este déficit comercial está tomando un fuerte cauce, atentando contra la estabilidad económica de varios sectores, especialmente el agropecuario e industrial y por consiguiente erosionando el crecimiento del PIB y la estabilidad de las políticas de desarrollo. La preocupación aumenta en la medida que se dan más rebajas arancelarias con el transcurrir del tiempo, dado que el panorama para Colombia se torna desesperante toda vez que EEUU es una economía grande, competitiva, subsidiada en algunos sectores y muy diversificada, con un fuerte desarrollo en el sector servicios, aspectos relativamente opuestos a su socio comercial.

Los fundamentos teóricos sobre comercio internacional cuentan con una amplia bibliografía que se torna bastante polémica debido a la diversidad de argumentos. Asimismo, desde la experiencia se detallan resultados poco unificados, la discusión académica no es reciente, por el contrario, ésta parte de los fundamentos del análisis mercantilista y además ha seguido alimentándose a través del debate académico desde sus diversas corrientes de pensamiento, a esto se suma la experiencia vivida en diferentes naciones del mundo, las cuales nutren el caudal de conocimiento sobre la materia.

Este trabajo se encuentra estructurado, así: en la primera parte se analiza el fundamento teórico, seguidamente el soporte y análisis del acuerdo del TLC entre EEUU y Colombia y por último, las conclusiones y recomendaciones.

\section{Fundamento Teórico.}

Para entender el acontecer de Colombia en materia de política comercial, es necesario un breve recorrido por las teorías ligadas a esta materia.

El mercantilismo ligado a la fuerte presencia del Estado, es quizás una teoría que parecía superada pero que hoy campea como en el siglo XVI y XVIII, en esta se defendía el control del comercio internacional y de la moneda por parte del Estado, de tal manera que sólo se debería importar lo que no se producía en el país y se propugnaba por una balanza comercial superavitaria. 
Tanto Adam Smith (1958) con la teoría de las ventajas absolutas como David Ricardo con las ventajas comparativas, se ubican en la teoría de la especialización, fueron desafiantes y contrarias al mercantilismo; no obstante, Malthus (1951) y Smith sobrepasan la libertad de mercado de mercancías y lo extienden a la movilidad laboral.

Los militantes de la Escuela Austriaca, Mises (2004) y Hayek (1997) defienden los postulados clásicos del comercio y destacan la importancia y bondades de la movilidad laboral internacional, igualmente Simon (1989), aunque este último no es considerado como austriaco por algunos autores, si comparte afinidad en el sentido de la migración internacional; aduciendo que los emigrantes pueden ser producto de crisis económicas ante malas prácticas económicas de Estado, aunque este fenómeno es multicausal (Gómez, 2010).

La orientación neoclásica defiende el clasicismo económico y le da gran importancia a la tasa de cambio e indica que debe ser flotante; asimismo, se encamina al control de la inflación como es defendida también por el monetarismo, pues el desbordado nivel de precios es un factor que resta competitividad. Tanto Reinhart como Rogoff (2010) dan trascendencia a la influencia de la deuda como proporción del PIB, esta no debe superar el $90 \%$ para no poner en peligro la capacidad de competitividad internacional. Paul Krugman en una posición Neokeynesiana se opone a esta visión y la considera un peligro para salir de la crisis de 2008 y le sindica de destructora del empleo y de crecimiento económico.

Por otro lado, la teoría de las proporciones factoriales de Heckscher y Ohlin (HO), contempla la ventaja que pueden tener los países siempre que se dediquen a producir el bien elaborado intensivamente con el factor que se encuentra en mayor proporción en el país, persiguiendo con esto unos menores costos, Leontief desvirtúo esta teoría para el caso de EEUU, bajo la denominada Paradoja de Leontief.

Michael Porter, propende por transformar las ventajas comparativas en competitivas y afirma que éstas se logran interrelacionando cuatro atributos: 1. Dotación de factores, 2. Examen de la demanda 3. Análisis de proveedores y competidores, en el ámbito internacional, 4. Examen del contexto para la creación, organización y manejo de las empresas, así como el establecer el grado de rivalidad a nivel de nación (Hill, 2011). La organización, administración, análisis de oferta y demanda, son elementos fundamentales en la competencia internacional en esta línea de pensamiento.

Krugman bajo el neokeynesianismo, justifica el porqué algunos países comercian internacionalmente con un mismo tipo de bien (comercio intraindustrial); teoría que está basada en economías de escala y en la cual se explica que a mayores volúmenes de producción, menores costos; adicionalmente se puede presentar una oferta diversificada. 
Prebisch y Singer sientan las bases de la teoría de la dependencia hacia la década de los años cincuenta del siglo pasado; consideran que el comercio internacional favorece más a los países desarrollados que a los menos desarrollados desde lo económico, esto se fundamenta en que los primeros se especializan en productos manufacturados que poseen mayor valor agregado, mientras que los últimos, en productos primarios con poco valor agregado; por lo tanto, se genera un deterioro en los términos de intercambio producto de las diferencias de precios (precios de bienes exportados/ precios de bienes importados), Bielschowsky (1998). Se formuló entonces, el modelo de sustitución de importaciones con el fin de promover tanto el desarrollo industrial como subsidios a la industria nacional para alcanzar mayores niveles de competitividad y desarrollo.

El comercio intraindustrial es una modalidad de comercio bajo competencia imperfecta y se refiere al intercambio de productos similares aunque con características diferenciadoras, dentro de la misma industria; como se mencionó anteriormente, se puede dar por las economías de escala y la diferenciación de productos, ejemplo: el mercado de vehículos de diferentes marcas; en contraste, el comercio interindustrial se da entre diferentes industrias y países con desigual nivel de crecimiento, en él se promueve la especialización mediante la reducción de costos, por ello encaja en las ventajas comparativas (Krugman, Obstfeld y Melitz, 2012).

Finalmente, para reafirmar que el mercantilismo no ha desaparecido sino que se mantiene, Amsdem (1992) y Sally (2011) confirman el fuerte proteccionismo de Korea para el primero y China para el segundo en sus inicios de industrialización, mediante el mecanismo de aranceles que se fueron liberando en la medida de que alcanzan un mayor grado de competitividad. Hoy en día, la política de EEUU en cabeza del presidente Donald Trump se ha reafirmado en un afanoso proteccionismo que ha llevado a tensiones mundiales entre China, EEUU y la Unión Europea. Estas políticas se esgrimen bajo el argumento de reducir el creciente desempleo a nivel nacional y sus consecuencias en materia de estabilidad política, pero este pasa por otras explicaciones que no son tenidas en cuenta como la automatización y la mejora de los sistemas de información (Harrison, 2017).

\subsection{Naturaleza y origen de los tratados de libre comercio.}

Debido a las pugnas comerciales entre Francia e Inglaterra, estos dos Estados se vieron obligados a firmar el primer acuerdo comercial bajo el tratado de Cobden-Chevalier en 1860, en éste no sólo se rebajaron aranceles sino que también se eliminaron barreras al comercio, en ambos sentidos para diversos productos; este antecedente gestó la proliferación de acuerdos bilaterales en la región, hacia el año de 1875 casi toda Europa marcaba valores mínimos en aranceles. Con la vigencia del Acuerdo General 
sobre Aranceles Aduaneros y Comercio (GATT, por su sigla en inglés) en 1948, se empieza a dar marcha a los acuerdos multilaterales, consolidándose éstos con la creación de la Organización Mundial del Comercio (OMC) en 1995 (Grossman, 2016).

Los acuerdos de libre comercio actúan como estructuras políticas activas permitiendo y facilitando las transacciones, además se negocian tanto aranceles como barreras no arancelarias, acceso a mercados, normas, plazos, inversión extranjera directa, circulación de capitales, derecho de patentes y regulaciones ambientales. El avance en las telecomunicaciones, medios de transporte, nuevas tecnologías y procesos industriales han facilitado y agilizado la realización de intercambios (Beltrán, 2017; Rodrik, 2018).

Es necesario recalcar que hoy en día, los contenidos de los tratados y acuerdos comerciales firmados se hacen mucho más amplios en términos de los artículos que los componen, lo cual se explica en la mayor complejidad de las negociaciones, entrando en ellos nuevos aspectos a considerar. Por otro lado, los acuerdos de libre comercio exigen una constante revisión que permita evaluar sus aspectos teóricos, implementación de políticas activas y, por supuesto, los resultados obtenidos.

$\mathrm{Al}$ analizar los resultados tanto de la integración económica como de algunos tratados comerciales se encuentran dos enfoques bien diferenciados en cuanto a sus efectos en el crecimiento, desarrollo económico y en lo emigratorio poblacional, resultando incluso contradictorios. El primero, asegura que los tratados no son muy beneficiosos en términos de crecimiento, dada la disparidad entre las naciones, en cambio, el segundo afirma que éstos fortalecen el crecimiento y desarrollo económico evitando las emigraciones y conjurando los problemas de violencia, derivados de la falta de oportunidades laborales.

De acuerdo a Sassen (1988) y Lim (1993), la creciente ola de integración económica de los países tiende a incrementar, más que a reducir las presiones migratorias. Alba (2005), afirma que la incorporación al mercado mundial no garantiza el evitar las migraciones ni mucho menos el alcanzar la convergencia, mientras la U.S. Commission for the Study of International Migration and Cooperative Economic Development (1990), asegura que en el corto plazo la migración aumentará pero que en el largo plazo las políticas de apertura económica y el dinamismo del mercado conducirán a la convergencia, reduciendo ostensiblemente el nivel de las presiones migratorias, ya que se habrá atacado su principal causa. Las relaciones de domino del llamado neoliberalismo, son importante entenderlas como lo señalan Vite, Tapia y González (2011) para entender cuál es la capacidad de negociación que tienen los países de economías más pequeñas frente a las grandes en el proceso de globalización y dominación. 
A pesar que las políticas comerciales preferenciales por parte de los países desarrollados hacia los de menor desarrollo han tenido, en teoría, como principios el reducir la emigración, evitar economías ilegales así como disminuir algunos factores de violencia, se observa que el Tratado de Libre Comercio entre México, Canadá y EEUU (TLCAN) firmado en diciembre de 1992, que entró en vigencia en 1994, no ha podido contener el flujo de emigrantes desde el primer país hacia los otros dos. Aunque en EEUU, durante el gobierno de Bush, luego de Obama así como el de Trump se ha venido realizando un control migratorio muy fuerte; la gran afluencia de ciudadanos extranjeros ha sido considerada un problema de orden nacional, de tal manera, que se ha buscado el cerramiento fronterizo a través de muros y mediante leyes anti-inmigratorias, transformando así el deseo de bienestar por parte del inmigrante y otorgándole como consecuencia de estas medidas persecutorias, un carácter delictivo en nombre del gobierno y la seguridad nacional con lo cual el problema no se soluciona, por el contrario se agrava.

Por otra parte, dentro del contenido de la Constitución Política de Colombia (CPC) en su capítulo 8 De las Relaciones Internacionales se señala al Estado como promotor de la internacionalización de las relaciones políticas, económicas, sociales y ecológicas de este país, teniendo siempre presente que las relaciones que por este caso se realicen, deben estar fundamentadas en el trato equitativo, recíproco y ser conveniente a nivel nacional. (Artículo 226, CPC). Ante lo cual se le otorga al gobierno nacional una serie de deberes u obligaciones para que las negociaciones a que haya lugar en el marco de dicho artículo, propendan por el bienestar de las naciones firmantes (CPC, 1991).

La relación comercial de Colombia y Estados Unidos está enmarcada desde la teoría económica como complementaria: mientras Colombia se dedica a exportar productos primarios derivados de la minería (petróleo, carbón, níquel, oro y piedras preciosas) así como del sector agropecuario (café, flores y banano, especialmente) y algunas manufacturas no complejas como ropa; EEUU es un país altamente industrial que exporta maquinaria, petroquímica, productos farmacéuticos y capital; aportando, por lo tanto, un altísimo valor añadido en sus exportaciones, sin olvidar la explotación de capital intelectual y de patentes; este país exporta también productos primarios subsidiados, los cuales compiten con los nacionales de Colombia desvaneciendo con estos hechos, la teoría de la complementariedad.

En la literatura académica, diferentes investigaciones han demostrado que el libre comercio por sí solo no garantiza el crecimiento económico, incluso puede ponerlo en peligro. Como lo sugiere (Todaro y Smith 2006; Dingemans y Ross 2012), para alcanzar éxito en el crecimiento y desarrollo económico se sugiere el acompañamiento de políticas de gobierno activas, asimismo, el exportar productos con 
mayor valor agregado, lo que permite medir la calidad de las exportaciones. Adicionalmente, la diversificación de productos de exportación resulta relevante, aunque se debe contar con que estas medidas estén acompañadas de la agregación de mayor valor, mecanismo que puede servir para cobertura de riesgos, muy propios en los vaivenes del mercado.

Analizando la evolución de las exportaciones entre 2013 y 2016 de Colombia, Chile, México, Brasil, Perú y Ecuador, de acuerdo a Bermúdez e Ibáñez $(2017,19)$,

Es Colombia el país que más se vio afectado por el choque de precios y la caída de la demanda internacional. Esto se debe, tal como se mostró anteriormente, a que es el país de la región que menos diversificada tiene su cesta exportable y está más concentrada en la venta de bienes mineros.

La poca diversificación y calidad en las exportaciones puede apoyar teóricamente, resultados poco satisfactorios en términos de crecimiento, desarrollo y generación de nuevos empleos para Colombia y Latinoamérica; además, señala la vulnerabilidad de estas economías ante una caída en la demanda mundial y el descenso de los precios de materias primas internacionales; por lo que se puede afirmar que no tiene los mecanismos de amortiguación ante estos choques, derivando en economías muy frágiles.

Las anteriores observaciones ameritan el trazado de nuevas estrategias y tácticas fundamentadas en la calidad y diversificación de las exportaciones, de forma permanente y que adicionalmente impliquen cambios estructurales, ya que no basta únicamente con la firma del acuerdo o tratado comercial.

Una de las mayores debilidades que presenta el mercado latinoamericano, aparte de las enumeradas anteriormente, es un comercio intrarregional muy débil comparado con Asia y Europa. En Colombia, las exportaciones están clasificadas de acuerdo al tamaño de las empresas, por departamentos de origen y países de destino, ante lo cual las empresas de menor tamaño presentan una alta fragilidad, no alcanzando la requerida experiencia en las exportaciones y además los costos resultan ser determinantes. Ante lo cual, la muerte de las empresas en Colombia es muy alta, muchas de ellas desaparecen incluso sin haber alcanzado la madurez.

Sin embargo, los beneficios de cualquier proceso de integración pueden ser más notorios si las naciones firmantes logran especializarse y potencializar tanto la producción como la comercialización de aquellos sectores en los que ya poseen ventajas. Nueva Zelanda, Canadá, Noruega y Australia son ejemplos de que la especialización en el sector primario puede generar efectos positivos en el crecimiento económico, siempre que este enfoque privilegie este sector y que además contemple otras directrices de política económica en las que puedan ampliarse otros. (Ibáñez y Bermúdez, 2017) 
En un estudio para los años 2010 a 2015, Bernal (2017) encuentra que sólo un $2.8 \%$ de las empresas activas exportó al menos una vez, de este valor sólo el $0.9 \%$ correspondió a microempresas y $6.1 \%$ a pequeñas empresas. Las empresas grandes representan el $95 \%$ de las exportaciones mientras que las micros, pequeñas y medianas empresas participan con el $5 \%$.

Dentro de los elementos que pueden explicar las bajas exportaciones se encuentran la falta de capital físico y humano altamente calificado, algunas barreras arancelarias y para-arancelarias, políticas de Estado poco pertinentes, precios no competitivos en los comercios internacionales, asimismo inadecuada infraestructura de transporte.

Adicionalmente, la fuerte dependencia de Colombia de las exportaciones mineras, genera a su vez demasiada vulnerabilidad, dada la propensión a incubar procesos revaluacionistas, haciendo la economía colombiana, por lo demás, proclive a la llamada enfermedad holandesa, la cual rivaliza con el sector industrial y agropecuario, además no se da una reinversión de utilidades, es intensiva en capital y genera poco empleo.

Por otra parte, tanto el dominio como el uso de las tecnologías de la información y la comunicación (TIC) en el comercio internacional de los servicios en América Latina ha comenzado a generar cierto interés y despliegue; situación que plantea varios interrogantes, sin embargo en los últimos años han existido algunos acuerdos como el Acuerdo de Asociación Transpacífico (TPP), el Acuerdo Transatlántico sobre Comercio e Inversión (ATCI) y la Asociación Económica Integral Regional (RCEP, su sigla en inglés), los cuales han promovido la reducción de barreras no arancelarias. La Organización Mundial de Comercio a través de los acuerdos de comercio de servicios y que incluye a la Unión Europea ha hecho un esfuerzo de negociación sobre los mismos; además los EEUU buscó mediante el TPP ejercer dominio en el mercado digital ante el inminente avance de China. No obstante, en los Estados Unidos estas regulaciones han quedado inciertas con la llegada de Trump, debido a sus planteamientos de salida de algunos acuerdos así como la renegociación de otros tantos.

Sobre los flujos digitales transfronterizos, en un estudio de la CEPAL $(2017,39)$ se plantea lo siguiente:

Los acuerdos comerciales de los años noventa resultan insuficientes para gobernar los flujos digitales transfronterizos, que están creciendo de manera exponencial. Mientras el espacio para desarrollar políticas industriales tradicionales se ha reducido marcadamente producto de los acuerdos de la OMC y de los acuerdos comerciales y de Inversión Norte-Sur, la economía digital permanece menos regulada. Ello deja espacios a los gobiernos para implementar medidas como el bloqueo de ciertos sitios de Internet e imponer requisitos de localización de servidores o exi- 
gencias a los proveedores extranjeros de revelar el código fuente de sus programas. En este contexto, actores como China, los Estados Unidos y la Unión Europea compiten por influir en la regulación del comercio digital mundial, con visiones y modelos muy heterogéneos.

Indudablemente, el mercado digital es una apuesta que América Latina y el Caribe y por consiguiente Colombia, no puede estar ausente ni substraerse de este mercado, sin embargo esto amerita mayor conocimiento, ya que aunque existe incursión en el mismo, esta debe potencializarse a mayor escala, lo que implica necesariamente más estudios de investigación que otorguen una mayor profundidad en el conocimiento de la materia.

En los tratados de libre comercio, especialmente con la Unión Europea, la protección de normas laborales comienza a ser parte de dichos acuerdos; sin embargo todavía se considera ineficiente en su cumplimiento (Marx, Ebert y Hachez, 2017). Estos son algunos de los elementos que deben comenzar a considerarse dentro de los posibles futuros tratados y acuerdos comerciales que Colombia decida llevar a cabo, como firmante de convenios en la Organización Internacional del Trabajo (OIT) y que ya están presentes en el TLC entre Colombia y EEUU.

Desde el punto de vista de los resultados de los tratados se denota, según Rodrik (2018) que las ganancias de los países desarrollados resultan ser las pérdidas para los países en desarrollo; igualmente, que los consumidores de estos últimos países tienen que soportar y pagar precios muy altos por productos farmacéuticos o de mayor complejidad científica y tecnológica, lo cual permite la obtención de grandes utilidades a los monopolios de los países desarrollados, ya que estos tienen una posición fijadora de precios. Otro gran beneficio que se consigue mediante estos tratados, está relacionado con la ventaja de los países de mayor capacidad económica para demandar en tribunales internacionales a naciones pequeñas causando con ello perjuicios monetarios, cuando sus intereses se encuentran amenazados por cambios de impuestos, legislaciones y expropiaciones. No obstante, para este autor, los acuerdos comerciales podrían ofrecer un mercado más libre y con mutuos beneficios por el hecho del mayor acceso al mercado, aunque deberían estar menos fundamentados en los aranceles, barreras no arancelarias y más sobre las regulaciones y reglas al interior del país.

$\mathrm{Y}$ es que en la firma de los tratados se observan privilegios sobre corporaciones frente al trabajo o aspectos medioambientales a la vez que pululan los cabildeos en los Comités Consultivos en los que están presentes muchos grupos a través de sus asociaciones gremiales, interesados en actividades comerciales.

No sólo por la complejidad sino también por la dinámica de los tratados de libre comercio, se exige un examen muy minucioso de estos, más si se tiene en cuenta que el número de aristas a considerar se amplía, en la medida que transcurre el tiempo, 
pues las fronteras de acuerdos arancelarios y no arancelarios se ven traspasadas por peticiones de derechos de patentes, derechos de autor, registros de calidad, cumplimiento de certificaciones, normativas sobre medio ambiente y laborales, controles de calidad, la aceptación de órganos de control y vigilancia, sumado a esto las fuertes presiones de ciertos grupos gremiales.

\section{Tratado de Libre Comercio TLC entre Colombia y EEUU.}

A mediados del siglo XX es importante diferenciar tres etapas significativas para el comercio de Colombia con el exterior; la primera arranca en 1950-1990 y es denominada modelo de sustitución de importaciones, la segunda contempla el periodo 1991-2011 se dan dos acuerdos preferenciales ATPA (1991-2001) - ATPDEA (20022008) y la tercera de 2012 a 2018 con el funcionamiento del TLC.

Los acuerdos ATPA (Ley de preferencias arancelarias andinas) y ATPDEA (Ley para la erradicación de drogas y promoción del comercio andino), la primera fue expedida el 4 de diciembre de 1991 por un período de diez años que finalizó el 4 de diciembre de 2001; esta ley fomentaba de manera unilateral las exportaciones hacia EEUU provenientes de algunos países andinos cuyas economías estaban fuertemente vinculadas al tráfico ilegal de drogas, entre ellos Colombia. En este sentido se generaba un compromiso por parte de estos países para combatir la producción y comercialización de estupefacientes desde sus territorios. Durante estos diez años se estableció un comercio libre de aranceles para 5.600 productos colombianos.

Una vez finalizada la vigencia del ATPA, surge el ATPDEA para el período entre octubre de 2002 y diciembre de 2008, el cual amplió en 700 nuevos productos con ingreso preferencial, además del acuerdo anterior tenían que respetar los acuerdos de la Ronda de Uruguay así como normas sobre patentes y laborales (Beltrán, 2013; De Micco, 2014). Con la firma de estos dos acuerdos se generaba un beneficio mutuo: por un lado EEUU buscaba reducir el ingreso de estupefacientes a su país y por el otro Colombia incrementaba sus exportaciones.

El Tratado de Libre Comercio (TLC) entre Colombia y EEUU se caracteriza por ser un tratado bilateral y se define como un acuerdo comercial que propende por la consolidación de un mayor mercado bilateral en el que se incrementen las oportunidades para los diferentes sectores económicos a nivel nacional; consiste en un acuerdo mediante el cual estos dos países deciden reglamentar sus relaciones comerciales, de tal forma que se pueda incrementar tanto el flujo comercial como de inversiones para alcanzar un mayor nivel de crecimiento y desarrollo socioeconómico.

A simple vista, este tratado representa una valiosa oportunidad para la economía colombiana, el poder comercializar una gran cantidad de bienes de fabricación nacional en el apetecido mercado de los EEUU, dada la consideración que se tiene de 
éste como primera potencia mundial; el abastecer de diversos tipos de bienes a 313 millones de habitantes (año 2012) representa a la vez un gran reto para la economía nacional. Aunque es necesario reconocer que este país no es el único que firma un tratado de este tipo con los EEUU, por lo cual el nivel de productividad y competitividad que este tenga durante la puesta en vigencia del tratado y el que logre alcanzar serán fundamentales para el exitoso desarrollo de las negociaciones, ya que le permitirán, por un lado, alcanzar cierta solidez en el mercado y por el otro competir tanto con los precios domésticos de los EEUU como con los otros socios comerciales de éste.

Tres fechas resultan clave en el análisis del TLC entre Colombia y EEUU: el 22 de noviembre de 2006 se da la suscripción del acuerdo; 12 de octubre de 2011 su aprobación por parte del Congreso de los Estados Unidos de América y el 15 de mayo del 2012 entrada en funcionamiento del mismo.

Para comprender el funcionamiento del Tratado de Libre Comercio firmado, a continuación se muestran algunos análisis gráficos para Colombia y EEUU.

\section{Gràfico 1}

Balanza comercial de Colombia con EEUU 1990-2017

\section{(millones de dòlares)}

30000

25000

20000

15000

10000

5000

0

$-5000$

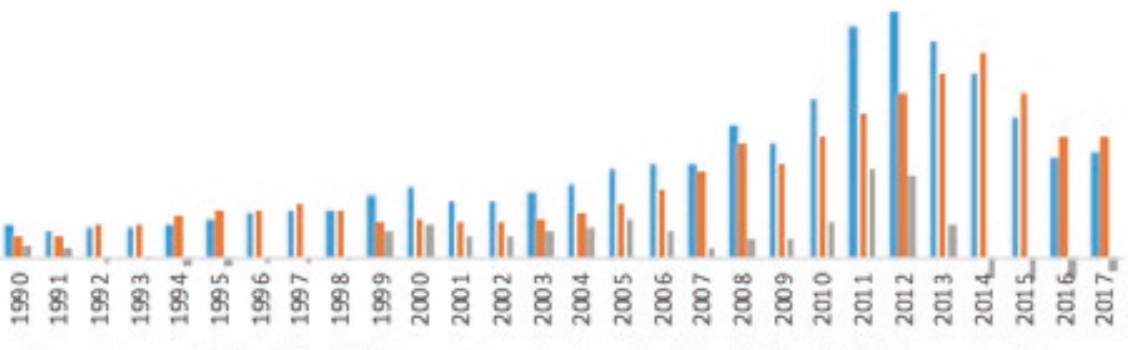

= Exportaciones de Colombia a EEUU

= Importaciones de Colom bia desde EEUU $=$ Deficit

Fuente: elaboraciòn propia, datos DANE.

Segùn los datos del gràfico 1, las exportaciones para el perìodo 1990-2017 tuvieron una tasa de crecimiento promedio de $6.3 \%$ y $8.6 \%$ para las importaciones, mientras que en el período (1991-2011) de vigencia de los acuerdos preferenciales ATPA y ATPDEA, la tasa de crecimiento promedio para las exportaciones fue $12.5 \%$ y para las importaciones $2.3 \%$, no obstante, entre los años 2014 y 2017 se presenta un dèficit acumulado de 7.908 millones de dòlares estadounidenses. A pesar de presentarse en 
el periodo 2014 - 2017, una fuerte devaluaciòn del peso con respecto al dólar, no se logró el impacto esperado en las exportaciones, lo que puede estar sustentado en la poca diversificaciòn de la canasta exportable y en la fuerte dependencia de las manufacturas y productos procesados nacionales de la importación de materias primas estadounidenses. Ante lo cual, no se evidenciò la mayor competitividad de las ventas colombianas y por el contrario, se incrementaron las compras en el extranjero.

Este resultado enciende las alarmas en los sectores productivos nacionales. Cabe recalcar, que en el perìodo de vigencia de los acuerdos preferenciales ATPA y ATPDEA no se presentaron deficit importantes, por el contrario, en casi todo el perìodo principalmente en este ùltimo la balanza comercial fue superavitaria. Esto indica un periodo favorable vinculado a los acuerdos ATPA y ATPDEA, explicado por las preferencias arancelarias y no el TLC, este ùltimo es desconcertante a la vista de sus resultados.

\section{Gràfico 2}

Comercio Colombia - EEUU 1994-I a 2017-IV

(millones de dòlares)

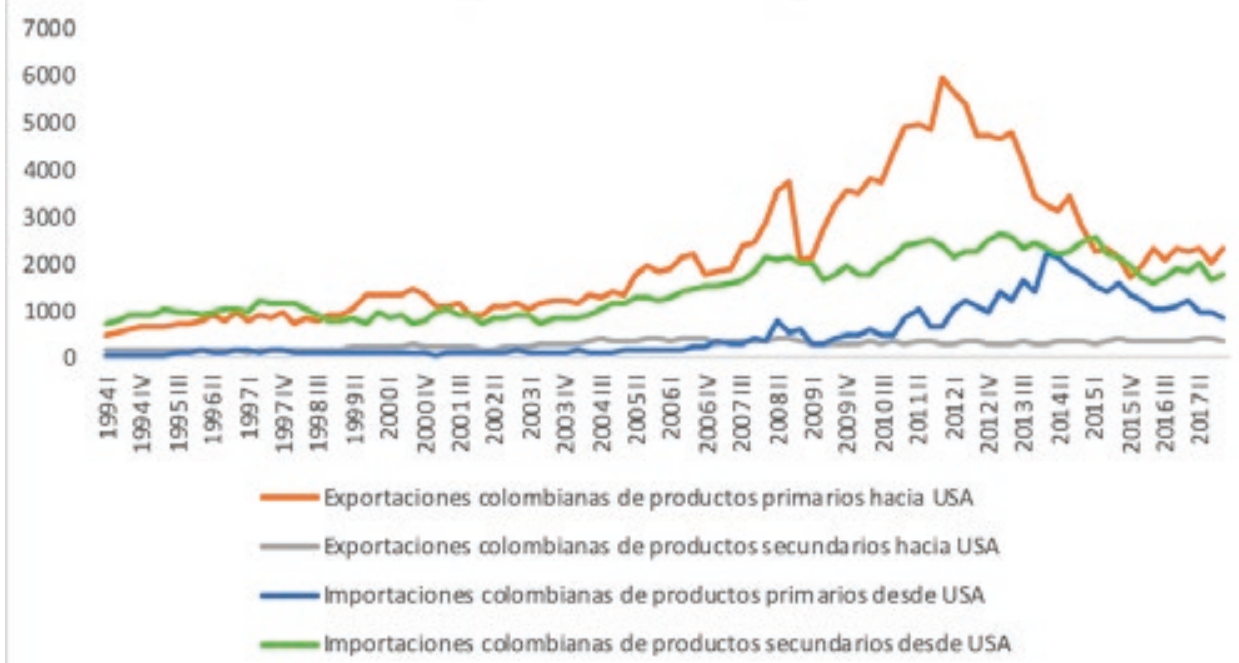

Fuente: elaboraciòn propia, datos DANE-DIAN.

Vistos los datos correspondientes al gráfico 2, en cuanto a las exportaciones de productos primarios desde Colombia hacia EEUU, para el período entre 1994-I y 2017IV, estas registran una tasa de crecimiento promedio de $2.5 \%$ con fluctuaciones 
muy importantes, derivadas de los precios tanto del café, banano, petróleo como de minerales especialmente. La importación de productos primarios de Colombia desde EEUU registró un crecimiento promedio de $6.6 \%$.

En cuanto a las exportaciones de productos secundarios desde Colombia hacia EEUU, para el período analizado entre 1994-I y 2017I-V, estas registran una tasa de crecimiento promedio de $1.6 \%$ que ha permanecido sin fluctuaciones importantes. La importaciòn de productos secundarios de Colombia desde EEUU registrò un crecimiento promedio de $1.5 \%$.

A la luz de los resultados observados, es preocupante el crecimiento de las importaciones de productos primarios cuando se esperaría todo lo contrario. A partir de 2007IV, las exportaciones de productos secundarios se colocaron por debajo de la importaciòn de productos primarios, con lo cual se està indicando que la ganancia històrica en el perìodo de analisis se viene perdiendo y cediendo a la importaciòn de productos de origen primario. Las importaciones de productos secundarios estan asociadas a las exportaciones de productos primarios; cuando estos ùltimos suben, los otros responden de igual manera.

\section{Gràfico 3}

Comercio Agropecuario entre Colombia y Estados Unidos periodo 1994-I y 2017-IV

\section{(millones de dòlares)}

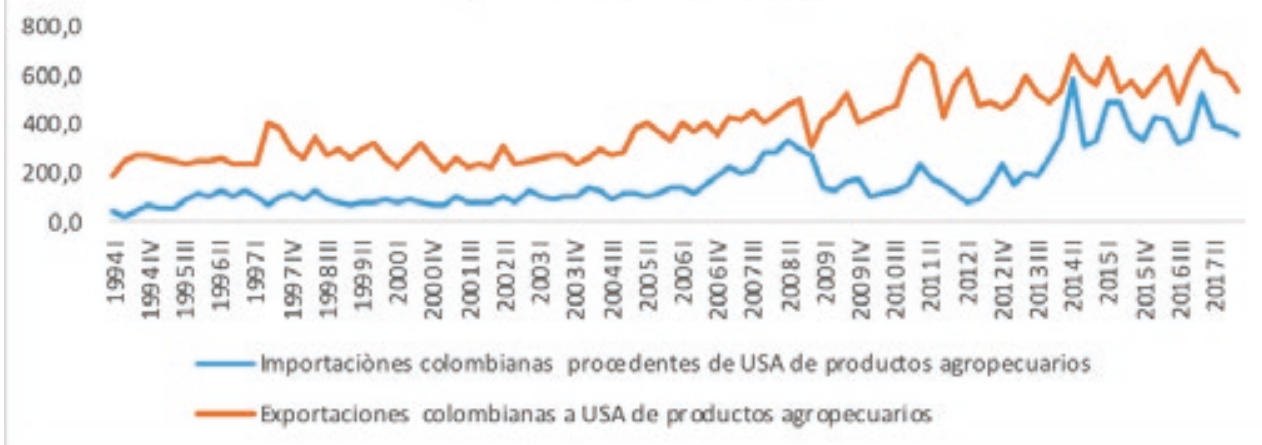

Fuente: elaboraciòn propia, datos DANE-DIAN

Se puede observar a través del gráfico 3 que, las exportaciones colombianas de productos agropecuarios hacia EEUU para el período 1994I - 2017IV registran en promedio una tasa de crecimiento de $2.4 \%$ y su contraparte, las importaciones, en $5.9 \%$ y comienza con un salto vertiginoso a partir del primer trimestre de 2014. 
Desde el año 2014 se denota un cambio estructural del comercio del sector agropecuario a favor de EEUU frente a Colombia, el cual coincide con el período posterior a la ratificación del TLC entre estos dos países, mostrando además que uno de los sectores más golpeados por este tratado ha sido justamente el agropecuario. Sector considerado tradicionalmente como fuerte generador de crecimiento de la economía colombiana.

En esta parte, vale la pena señalar como el cambio de comportamiento en la balanza comercial del sector agropecuario, que ya se había iniciado con la apertura económica de 1991 durante el gobierno de César Gaviria, se acentúa con la ratificación del Tratado de Libre Comercio con EEUU, lo cual no representa sólo un problema de balanza comercial sino que también puede poner en peligro la seguridad alimentaria, pues se ha cedido la soberanía en términos de producción de alimentos.

Relaciones de tamaño. Para entender a Colombia y EEUU en la capacidad de negociación, es importante determinar las relaciones de tamaño de sus economías y para esto se establece la proporción del producto total de Colombia y de EEUU (Pib$\mathrm{col} /$ Gdpusa), exportaciones totales de Colombia y EEUU (Expcol/Expusa), importaciones totales de Colombia y de EEUU (Impcol/Impusa), estas relaciones también se hacen en términos per cápita para medir su productividad.

\section{Gráfico 4}

Relación entre el tamaño del producto y las transacciones comerciales Colombia - EEUU años 1990-2017

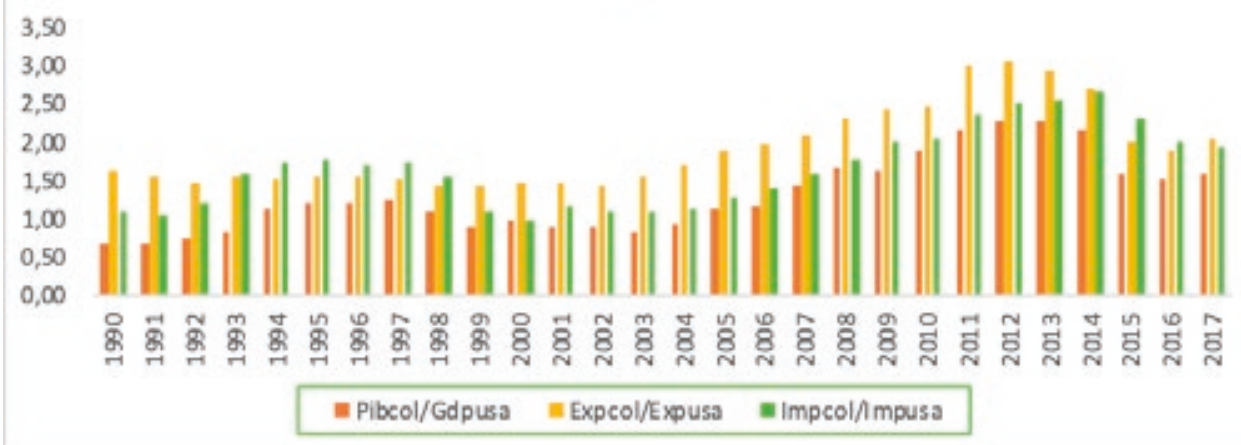

Fuente: Elaboración propia, datos DANE-DIAN y Banco Mundial.

Para el período analizado entre 1990-2017 se observa que en promedio Colombia representa el $1.31 \%$ del producto total de EEUU y en la relación de exportaciones 
totales $1.92 \%$ y sobre las importaciones totales $1.67 \%$. Relacionadas las proporciones totales promedio en términos per cápita se encuentra que, el producto de cada colombiano es de 3.944 dólares mientras para un estadounidense es de 40.956 dólares; en cuanto a exportaciones, un colombiano exportó 653 dólares y un estadounidense 4.588 dólares, examinando las importaciones un colombiano importó 717 dólares en contraste un estadounidense 5.862 dólares. De estos resultados se deduce el bajo peso de la economía colombiana frente a la estadounidense, asimismo en términos de productividad.

El tamaño de la economía resulta determinante en los procesos de negociación y establecimiento de condiciones de tratados y acuerdos. La conveniencia de los tratados comerciales que se puedan dar entre dos países tan dispares como son EEUU y Colombia en un régimen de mercado sin protecciones arancelarias y sin preferencias se juega en favor del primero.

Vistos los anteriores resultados, se infiere el por qué el Acuerdo Comercial de Colombia con EEUU, TLC, está viviendo una etapa de prueba que ha sido desfavorable para Colombia, país que ha venido presentando un déficit comercial y además ha visto afectado su aparato productivo, pues algunos sectores de la industria y del sector agropecuario han sido los más perjudicados.

Esta situación amerita una revisión, por lo cual se debería aprovechar la coyuntura en favor de revisión de los tratados, formulada por el gobierno del presidente Donald Trump; aunque esta pueda ser vista como una oportunidad, algunos analistas ya planteaban una demanda sobre la misma.

Desde antes de la firma del acuerdo, especialmente sectores de la oposición al gobierno nacional así como algunos académicos hicieron reparos sobre el TLC, argumentando que Colombia no era una economía lo suficiente madura, para enfrentar al mercado de los EEUU y su desarrollo económico. De acuerdo a los resultados obtenidos, esta premonición de los sectores críticos al gobierno pareciera estarse cumpliendo.

\section{Conclusiones}

Este trabajo permite evidenciar que el TLC firmado entre EEUU y Colombia, parte de un desconocimiento de la teoría del comercio internacional, ya que se trata de una negociación entre una economía grande (alta capacidad de determinación) y competitiva para el caso de EEUU frente a una economía pequeña (sin capacidad de determinación) y baja competitividad como la colombiana. Para el período analizado entre 1990-2017 se observa que en promedio, Colombia representa el 1.31\% del producto total de EEUU y en la relación de exportaciones totales $1.92 \%$ y sobre las importaciones totales $1.67 \%$; así mismo el producto de cada colombiano es ape- 
nas el $9.34 \%$ con respecto al que produce un estadounidense promedio; en cuanto a las exportaciones, cada colombiano exportaría el $13.72 \%$ en relación a las de un estadounidense e importaciones $11.88 \%$. De estos resultados se deduce el bajo peso de la economía colombiana frente a la estadounidense así como en términos de productividad.

Las exportaciones colombianas para el lapso 1990-2017 obtuvieron una tasa de crecimiento promedio de $6.3 \%$, mientras que para las importaciones fue de $8.6 \%$. En el período de vigencia de los acuerdos preferenciales ATPA y ATPDEA no se presentaron déficits importantes, por el contrario, en casi todos los años de vigencia de estos acuerdos, la balanza comercial fue superavitaria. Se encontró que durante la permanencia de los acuerdos mencionados, las exportaciones crecieron a una tasa promedio de $12.5 \%$ y las importaciones al $12.3 \%$, resultado que es explicado por las preferencias arancelarias y no por el TLC. Los imponentes déficits comerciales (7.908 millones de dólares en los últimos cuatro años) se tornan desconcertantes y generan gran preocupación en los sectores productivos nacionales.

En las exportaciones de productos primarios colombianos hacia EEUU correspondientes al periodo 1994I-2017IV, se registra una tasa de crecimiento promedio de $2.5 \%$ con importantes fluctuaciones, derivadas de los precios internacionales tanto del café, banano, petróleo y minerales; mientras que las importaciones colombianas para el mismo sector, procedentes del mercado estadounidense, señalan una tasa de crecimiento promedio del 6.6\%. Adicionalmente, se encuentra que los productos agropecuarios colombianos exportados hacia los Estados Unidos presentan una tasa de crecimiento promedio del $2.4 \%$ mientras que los productos importados del mismo sector señalan una tasa de crecimiento de 5.9\%. Teniendo en cuenta los anteriores resultados, se genera una alarma sobre sus implicaciones en el desmantelamiento del sector agropecuario colombiano, que aunque datan de la apertura comercial de 1991 parecen agudizarse con el TLC.

Se manifiesta que los productos industriales colombianos exportados hacia EEUU para el período de análisis, han permanecido sin apreciables fluctuaciones, señalando una tasa de crecimiento promedio de $1.67 \%$; en contraste, las importaciones colombianas en el mismo sector registran en promedio una tasa de crecimiento de $1.5 \%$.

Colombia presenta una escasa diversificación en su canasta de exportaciones, canasta que está compuesta por productos primarios, especialmente agrícolas, pecuarios y mineros, con el agravante que éstos contienen bajo valor agregado, lo que hace a la economía colombiana vulnerable frente a una caída de la demanda mundial $\mathrm{y}$ ante el descenso de precios internacionales en materias primas. En este sentido, si Colombia persigue una mejora en materia de competitividad debería hacer un cambio en la composición de su matriz productiva, privilegiando con ello productos de mayor contenido en valor agregado. 
Del análisis anterior, se detecta que los términos de intercambio son poco favorables para el sector productor de Colombia frente a EEUU, por lo cual este país debe mejorar en el tamaño y diversificación de sus productos exportables, lo que incluso resulta más determinante que su tasa de cambio. Por lo tanto, para Colombia obtener una balanza comercial favorable no resulta suficiente el realizar devaluaciones competitivas, mediante la manipulación de su tasa de cambio.

$\mathrm{Al}$ parecer, la presión hacia la firma del tratado por parte de Colombia estuvo en cabeza del gremio de grandes comerciantes importadores que los ubica como los verdaderos beneficiarios de este país, pero no al sector productor agropecuario ni a la pequeña y mediana industria.

\section{Referencias}

Alba, F. (2005). Integración económica y políticas de migración: un consenso en revisión. [En línea] En: Migración México-Estados Unidos. Opciones de Política. El Colegio de México, p. 32-44. Disponible en: http://www.conapo.gob.mx/ work/models/CONAPO/migracion_internacional/MigracionOpPolitica/02.pdf [Consultado el 10 de abril de 2018].

Amsdem, A. (1992). Corea, un proceso de industrialización tardía, Grupo Editorial Norma, 442p. [Traducción de Ernesto Samper Nieto].

BeLtrán, L (2017). Integración y acuerdos regionales mundiales: una visión desde la economía y el derecho público internacional, editado por la Escuela Superior de Administración Pública (ESAP), Bogotá D.C, primera edición, 191.

Beltrán, L (2013). 20 años después del proceso de apertura económica: más mercados con poca diversificación exportadora. Revista Civilizar De Empresa y Economía, 4 (7), pp 9-26 doi: 10.22518/2462909x.243

Bermúdez, M. e IbÁÑEZ, D. (2017). Déficit comercial de Colombia en 2016: una mirada de política comparada. Revista Estudios Económicos, Vol. 1 No 1, Ministerio de Comercio e Industria de Colombia, Oficina de Estudios Económicos, pp.13-23.

Bernal, F. (2017). Análisis de las exportaciones colombianas según el tamaño de las empresas, 2010-2015. Revista Estudios Económicos, Vol. 1 No 1, Ministerio de Comercio e Industria de Colombia, Oficina de Estudios Económicos, pp.30-47.

Bielschowsky, R. (1998). Evolución de las ideas de la CEPAL, Revista CEPAL, número extraordinario, Santiago de Chile, octubre del 1998, pp21-45.

Comisión Económica Para América Latina (2017) Repunte del comercio regional en un contexto global incierto, en, Perspectivas del comercio internacional de América Latina y el Caribe (LC/PUB.2017/22-P), Santiago Chile, pp.29-78.

De Micco, P (2014). The US and EU free trade agreements with Peru and Colombia: A comparison, Policy Department for External Policies, European Parliament, 25p. Disponible en: http://www.europarl.europa.eu/RegData/etudes/briefing_note/ 
join/2014/522326/EXPO-INTA_SP\%282014\%29522326_EN.pdf［Consultado el 2 junio de 2018].

Dingemans, A. y Ross, C. (2012). Los acuerdos de libre comercio en América Latina desde 1990. Una evaluación de la diversificación de exportaciones. Revista CEPAL 108, pp.27-50. doi: 10.18356/00ca0826-es

Espinosa, A. y Pasculli, L. (2013). Visión agrícola del TLC entre Colombia y Estados Unidos: preparación, negociación, implementación y aprovechamiento. Revista Estudios y Perspectiva, Serie 25 CEPAL, abril de 2013, 89

Gómez, J. (2010). La migración internacional: teorías y enfoque, una mirada actual. Revista Semestre Económico, Volumen 13, No 26, pp. 81-100, Medellín Colombia.

Grossman, G. (2016). The purpose of trade agreements. NBER Working Paper No. 22070, March 2016, 55p. Disponible en: http://www.nber.org/papers/w22070 [Consultado el 5 de junio de 2018].

Harrison, A. (2017). The Changing Landscape for International Trade: Protectionism, Bashing China, and the American Worker, The Wharton School, University of Pennsylvania, NBER, and CEPR Jackson Hole Symposium, August 24-26, 2017. Disponible en: https://www.kansascityfed.org/ /media/ files/publicat/sympos/2017/harrison-remarks-jh.pdf?la=en [Consultado el 5 de junio de 2018].

HaYek, F. (1997). La fatal arrogancia: los errores del socialismo. Unión Editorial S.A, $2^{a}$ ed., obras completas volumen I, Edición Española al cuidado de Jesús Huertas de Soto,1997, 256.

HiLL, Charles (2011) Negocios Internacionales. Competencia en el mercado global $8^{\mathrm{a}}$ edición. Ed. Mc Graw Hill Mexico, 737.

Krugman, P., Obstfeld, M. y Melitz, M. (2012). Economía Internacional Teoría y Política 9a edición. Ed. Pearson, Madrid (España) 754.

Lim Lean, L. (1993). Growing economic interdependence and its implications for international migration. Documento presentado a la Reunión del Grupo de Expertos en Distribución de la Población y Migración organizado por la División de Población del Departamento de Desarrollo Económico y Social. Naciones Unidas-UNFPA, Santa Cruz, Bolivia, 18-22 de enero de 1993.

Malthus, T. (1951). Ensayo sobre el principio de la población. Editorial Fondo De Cultura Económica, México D.F., 619p. [Traducción de Teodoro Ortiz].

Marx, A., Franz, E., and Hachez, N. (2017) Dispute settlement for labour provisions in EU free trade agreements: rethinking current approaches. Politics and Governance, 2017,Vol 5, Issue 4, Pages 49-59, doi: 10.17645/pag.v5i4.1070

Mises, Lwdwig Von (2004). La acciòn humana: tratado de economía. Uniòn Editorial S.A., $7^{a}$ ed., Madrid, España, 1068p. [Traducciòn de Joaquin Reig Albiol]. 
Piraquive et al. (2017). Análisis del comercio internacional colombiano y diversificación de exportaciones (2002-2015): Canadá, Estados Unidos y Unión Europea. Archivos de Economía, Departamento Nacional de Planeación, Documento 457, Dirección de Estudios Económicos 17 de febrero de 2017, 158p. Reinhart, C. y Rogoff, K. (2010). Growth in a Time of Debt disponible en http:// www.nber.org/papers/w15639, Consultado el 30 de junio de 2018

Rodrik, D. (2018) What Do Trade Agreements Really Do? Journal of Economic Perspectives-Volume 32, Number 2-Spring 2018-Pages 73-90

SALLY, R. (2011). Chinese trade policy after (almost) ten years in the WTO: a post-crisis stocktake. ECIPE ocassional paper No. 2, 35p, editado en Bélgica. Disponible en: http://www.ecipe.org/app/uploads/2014/12/chinese-trade-policy-after-almostten-years- in-the-wto-a-post-crisis-stocktake.pdf [Consultado el 5 de junio de 2018].

Sassen, S. (1988) The mobility of Labor and Capital. Cambridge, Cambridge University Press, 224.

Simon, J. (1989) The economic consequences of inmigration. Basil Blackwell published in association with The Cato Institute, printed in the USA, 430.

Sмith, A.(1958). Una investigación sobre la naturaleza y causas de la riqueza de las naciones. Editorial Fondo de Cultura Económica, México D.F., 1958, 917. [Traducción de Gabriel Franco].

Todaro, M. y Smith, S.(2006) Economic Development. Boston, Pearson-Addison Wesley, 9 th ed, 851.

Vite, M., TAPia, G. y GonzÁlez, R (2011). ¿Es la inversión extranjera en México palanca de desarrollo en el contexto de la globalización?, en Avances recientes en teoría y práctica económica, Vol. I, Facultad de Economía «Vasco de Quiroga», Universidad Michoacana de San Nicolás de Hidalgo, México, pag.100-111. 
